\title{
Aprendiz versus Trabalhador: Adolescentes em Processo de Aprendizagem
}

\author{
Mayte Raya Amazarray ${ }^{1}$ \\ Luciana Dutra Thomé \\ Ana Paula Lazzaretti de Souza \\ Michele Poletto \\ Silvia Helena Koller \\ Universidade Federal do Rio Grande do Sul
}

\begin{abstract}
RESUMO - Este estudo objetivou conhecer a experiência de adolescentes em processo de inserção laboral. Participaram 10 adolescentes, de ambos os sexos, com idades entre 15 e 16 anos, em contrato de aprendizagem em empresa pública. Foi utilizada uma abordagem qualitativa, com aplicação de questionário biosociodemográfico e grupos focais. Criaram-se quatro categorias temáticas: ser adolescente, aprendiz versus trabalhador, significado do trabalho e futuro profissional. Constatouse indiferenciação entre os papéis de trabalhador e aprendiz. A experiência de aprendizagem foi percebida como situação privilegiada para a formação profissional. Expectativas acerca do futuro laboral revelaram insegurança e desinformação quanto ao mercado de trabalho. Evidenciou-se a importância da experiência para a construção da identidade de trabalhador e da realização de programas de acompanhamento junto a adolescentes aprendizes.
\end{abstract}

Palavras-chave: adolescente aprendiz; trabalho e juventude; inserção laboral.

\section{Apprentice versus Worker: Adolescents in Apprenticeship Process}

\begin{abstract}
This study aimed to know the experience of adolescents in labor insertion process. The participants were 10 adolescents of both sexes, aged 15 and 16 years old, with an apprenticeship contract at a public enterprise. It was used a qualitative approach, with the application of a biosociodemographic questionnaire and focal groups. Four thematic categories were created: being adolescent, apprentice versus worker, meaning of work and professional future. The results revealed fusion between the worker and apprentice roles. The experience of apprenticeship was perceived as a privileged practice for professional training. Expectancies about the professional future revealed insecurity and lack of information related to labor market. This study showed the importance of the experience of apprenticeship to build worker identities and of counseling programs for adolescents.
\end{abstract}

Keywords: apprentice adolescent; work and youth; labor insertion.

O trabalho infanto-juvenil é um tema de relevância social, que abrange aspectos econômicos, culturais e psicológicos, entre outros. Cada vez mais, o trabalho precoce de crianças tem chamado a atenção da sociedade para sua necessária erradicação, especialmente daquelas atividades insalubres e degradantes. Por outro lado, o trabalho dos adolescentes tema central deste artigo - continua a ser visto, em diversas instâncias, como algo naturalizado e necessário para as famílias de nível socioeconômico baixo. Essa visão desconsidera as implicações do trabalho na saúde, na constituição da identidade e na vida acadêmica dos jovens. Diante disso, nota-se a importância de medidas legais e políticas públicas que visem a proteger o trabalhador adolescente.

O Estatuto da Criança e do Adolescente (ECA) estabelece importantes diretrizes para a proteção da atividade laboral na adolescência. Segundo o ECA (Brasil, 1990), é proibido o trabalho a menores de 14 anos, exceto na condição de aprendiz. Por sua vez, a contratação de aprendizes, regulamentada pelo Decreto n ${ }^{\circ} 5598 / 2005$ (Brasil, 2005), assegura formação técnico-profissional e realização de atividades compatíveis

1 Endereço para correspondência: Universidade Federal do Rio Grande do Sul, Instituto de Psicologia. Rua Ramiro Barcelos, 2600, sala 104. Bairro Santa Cecília. Porto Alegre, RS. CEP 90035-003. E-mail:maytepsi@gmail.com. com a vida escolar e com o desenvolvimento físico, psicológico e moral do aprendiz. O contrato de aprendizagem pressupõe frequência escolar, horário especial para o exercício das atividades, programa de formação técnico-profissional e capacitação adequada ao mercado de trabalho. Assim, o Decreto impõe limites ao trabalho dos adolescentes, visando propiciar reais condições de aprendizagem e minimizar os impactos do trabalho precoce. A contratação de aprendizes é obrigatória para empresas submetidas ao regime da Consolidação das Leis do Trabalho, no número equivalente a, no mínimo, $5 \%$ e, no máximo, $15 \%$ dos trabalhadores. Como consequência, empresas têm inserido adolescentes em seu quadro funcional na condição de aprendizes que executam suas atividades protegidos pela legislação.

Para os adolescentes, o trabalho pode ter implicações positivas quando propicia aprendizagem e é revestido de significado. Por outro lado, pode trazer impactos para seu desenvolvimento quando as condições laborais se apresentam desfavoráveis. A execução de um trabalho em contexto adverso, comumente, acarreta consequências negativas para a pessoa em desenvolvimento. Por ser constituinte do ser humano, a experiência de trabalho é uma importante esfera na construção da identidade, sendo geradora de saúde, sofrimento e/ou doença (Codo, 1992). A estreita relação 
entre desenvolvimento, identidade e escolha profissional é apontada por Sarriera, Silva, Kabbas e Lopes (2001), sendo essa escolha o reflexo de como o jovem lida com sua crise de identidade e analisa o contexto sociocultural em que está inserido. Erikson (1950/1987) relaciona identidade e escolha profissional. Na formação da identidade, os adolescentes sintetizam identificações pregressas em uma nova estrutura psicológica, processo no qual três questões básicas estão presentes: a escolha da ocupação, a adoção de valores e o desenvolvimento de uma identidade sexual satisfatória. A escolha profissional, portanto, é formadora da identidade do jovem, o qual estrutura sua vida a partir dos compromissos ideológicos, pessoais e laborais que assume.

O contexto do mercado de trabalho atual, marcado pela reestruturação produtiva e por novos discursos gerenciais, define um ideal de trabalhador como flexível e competitivo. A esse respeito, Nardi e Yates (2005) analisam criticamente o mundo do trabalho contemporâneo e descrevem a existência de uma nova ética, baseada no individualismo, que modifica a relação subjetividade e trabalho, explicitando novas exigências para a inserção laboral. Sarriera e cols. (2001) constataram que, para jovens trabalhadores de classes populares, a inserção laboral representava a possibilidade de transformação de sua realidade social para uma perspectiva melhor de futuro. Contudo, esse estudo também identificou que, diante dos elevados índices de desemprego, o nível de sofrimento dos jovens aumenta e diminui a possibilidade de realizarem escolhas profissionais bem definidas. Por vezes, ainda que exista a inserção laboral, os empregos caracterizam-se por precariedade e descumprimento de leis trabalhistas - fato constatado por outros autores (Campos \& Francischini, 2003; Oliveira \& Robazzi, 2001). Frente a essa configuração do mundo laboral, o jovem pode orientar-se para uma opção profissional desvinculada de sentido, que o insere em formas de trabalho degradantes, alienadoras e desprovidas de reais oportunidades de aprendizagem - justamente no momento em que está definindo sua identidade pessoal e ocupacional.

No Brasil, estudos têm apontado efeitos negativos do trabalho sobre a saúde dos jovens trabalhadores (Asmus \& cols., 2005; Fischer, Oliveira, Teixeira, Teixeira \& Amaral, 2003; Fischer, Martins \& cols., 2003; Fischer \& cols., 2005), danos que podem ser evidentes apenas em estágios posteriores da vida. Em ambulatório especializado na saúde do trabalhador adolescente, Asmus e cols. (2005) identificaram que as principais patologias relacionadas ao trabalho são doenças osteomusculares, infecções respiratórias do trato superior, doenças alérgicas, problemas oculares e hipertensão arterial. As principais queixas não são originárias do processo de trabalho. Entretanto, quando existe nexo causal entre os problemas de saúde e a atividade laboral, os adolescentes não costumam relacionar os sintomas com o exercício profissional.

O estudo de Fischer, Oliveira e cols. (2003) revelou que, embora $87,6 \%$ dos adolescentes pesquisados se considerassem saudáveis, $81,6 \%$ informaram cansaço; $55,1 \%$, moleza; $46,3 \%$, sonolência diurna; $62,2 \%$, dores no corpo. O estudo identificou ainda associação entre trabalho e redução do sono, indicando que o horário laboral interfere no ciclo vigília-sono dos adolescentes, especialmente quando exercem funções em condições desfavoráveis, locais insalubres, com maiores exigências (físicas e mentais) e enfrentam falta de controle no trabalho. Em outro estudo com 781 adolescentes estudantes, Fischer, Martins e cols. (2003) identificaram que 604 deles tinham experiência de trabalho, dos quais $47 \%$ relataram já ter sofrido acidente de trabalho em ocupações prévias e $38 \%$ referiram danos relacionados ao trabalho atual. Foram identificados diversos fatores de risco, como estudar à noite, trabalhar com desconforto térmico, equipamentos perigosos, produtos tóxicos e demandas de esforço físico. Os meninos relataram acidentes com consequências mais graves do que as meninas, enquanto estas relataram mais dores no corpo, associadas a trabalhos domésticos.

Além das condições físicas, características psicológicas do posto de trabalho devem ser consideradas, tais como pressões de chefias, tomadas de decisão, raciocínio, entre outras. Um elemento negativo compartilhado por adolescentes trabalhadores refere-se à "muita responsabilidade", refletindo falta de experiência no trabalho, excesso de tarefas e, especialmente, exigências psicossociais geradoras de estresse e incompatíveis com seu momento de desenvolvimento (Oliveira, Fischer, Amaral, Teixeira \& Sá, 2005). Exigências psicológicas elevadas no trabalho - como baixo controle sobre as tarefas e alto volume de atividades - mostraram-se associadas a dores no corpo, maiores riscos de acidentes e redução do sono (Fischer \& cols., 2005). Ainda, baixa autoridade de decisão está associada a maiores jornadas de trabalho, com maior exposição a riscos e menos horas de estudo e lazer (Fischer \& cols., 2005).

É inegável a competição que se estabelece entre o trabalho e as atividades escolares, o lazer, a convivência familiar e as relações com pares. Alguns autores (Campos \& Francischini, 2003; Oliveira \& Robazzi, 2001; Oliveira, Sá, Fischer, Martins \& Teixeira, 2001, Oliveira, Fischer, Teixeira \& Amaral, 2003; Oliveira \& cols., 2005) já apontaram o comprometimento do processo de escolarização em adolescentes trabalhadores. Em seus estudos sobre as representações sociais dos adolescentes acerca da escola e do trabalho, Oliveira e cols. $(2001,2003,2005)$ identificaram que a relação trabalhoestudo comporta imagens sobre as dificuldades decorrentes da conciliação entre essas duas atividades. Tais imagens associam-se ao cansaço, à sobrecarga física e à falta de tempo para estudar, para descansar e para o lazer, tendo como consequências a falta de interesse na escola, a dificuldade em aprender e os altos níveis de estresse.

Embora a dupla jornada trabalho-estudo represente desgaste e esforço, os adolescentes desejam conciliar as duas atividades (Oliveira \& cols., 2001, 2003, 2005). Esses jovens associam elementos positivos à concomitância do estudo e do trabalho. Entre eles: a maior maturidade do aluno trabalhador, o aprendizado resultante do trabalho e a construção de um futuro que lhes permita ascender em uma carreira profissional, além de representar a possibilidade de superação da sua atual condição de classe. Nesse sentido, Oliveira e cols. (2003) afirmam que os benefícios percebidos pelos adolescentes da conciliação estudo-trabalho são morais, no sentido de se atribuir um status de adulto ao jovem, em função da assunção de responsabilidades. Trabalhos como os realizados por Campos e Francischini (2003) e Oliveira e Robazzi (2001) chamam a atenção para o fenômeno da "adultização", que 
pode se estabelecer quando o jovem toma responsabilidades precocemente para si, sem ter o desenvolvimento e maturidade necessários para lidar com tais demandas.

O trabalho precoce expressa a ideologia da valorização do trabalho, que o mostra como dignificante e almejado pelos pais porque afasta crianças e adolescentes da marginalidade (Asmus \& cols.., 2005; Campos \& Francischini, 2003; Guimarães \& Romanelli, 2002). A inserção laboral é associada pelos próprios adolescentes ao valor moral do trabalho, por meio de palavras como "bom", "importante", "enobrece o homem", "amadurecimento", "dinheiro" (Oliveira \& cols., 2001, 2003, 2005; Guimarães \& Romanelli, 2002). A condição financeira das famílias também é um importante fator na determinação do trabalho na adolescência. Asmus e cols. (2005) identificaram a família como a principal responsável pela inserção laboral dos jovens, razão pela qual estes não conseguiam vislumbrar o que significava para eles mesmos o trabalho, descrevendo-o como uma obrigação para ajudar na economia doméstica. Além disso, o trabalho representa independência e constitui a base para o consumo, ainda que em patamares mínimos, de bens valorizados socialmente e que a família não pode financiar.

O trabalho na adolescência apresenta particularidades que o coloca como questão complexa, que pode abarcar fatores de risco e de proteção para o desenvolvimento de jovens trabalhadores. Sabe-se da carência de estudos brasileiros que investiguem aspectos subjetivos e a visão dos próprios adolescentes, em especial após a última regulamentação do contrato de aprendizagem em 2005. Nesse sentido, o presente artigo propõe-se a descrever um estudo realizado com adolescentes em contrato de aprendizagem, com o intuito de conhecer a visão dos jovens em um contexto de trabalho protegido. Objetivou-se investigar a opinião dos participantes a respeito da adolescência, da motivação para ingressar no programa de aprendizagem, da experiência de ser aprendiz, do trabalho e do futuro profissional.

\section{Método}

\section{Participantes}

Participaram deste estudo 10 adolescentes, com idades entre 15 e 16 anos $(M=15,8$ anos; $S D=0,42)$, cinco de cada sexo. Todos os participantes frequentavam escolas estaduais; um estava no oitavo ano do Ensino Fundamental e os demais no $1^{\circ}$ e $2^{\circ}$ anos do Ensino Médio. Todos os adolescentes residiam com a família, sendo procedentes de Porto Alegre, Viamão e Gravataí.

\section{Instrumentos}

Foi utilizado um questionário biosociodemográfico (Dell'Aglio, Poletto, De Antoni, Teodoro \& Koller, 2005), que abordou aspectos como idade, sexo, escolaridade, características familiares, local de residência, relações com a escola, eventos de vida e uso de drogas. Utilizaram-se também as técnicas de grupo focal (De Antoni \& cols., 2001;
Morgan, 1997) e entrevista reflexiva (Szymanski, 2001) para obtenção dos dados.

\section{Procedimento}

O presente estudo compreendeu uma abordagem qualitativa de natureza exploratória-descritiva. Foi utilizada a técnica de grupo focal para discutir as temáticas da adolescência e do trabalho aprendiz com os adolescentes. Além disso, também foi utilizada a entrevista reflexiva, que possibilitou uma devolução dos resultados aos participantes e um momento de análise das discussões realizadas durante os grupos focais.

O presente estudo foi realizado em uma empresa pública, de grande porte, que presta serviços para o Governo Federal, na unidade localizada em Porto Alegre. Seis meses antes da realização do estudo, tal empresa havia implantado um projeto de aprendizagem para adolescentes em parceria com uma Organização Não-Governamental (ONG), a fim de se adequar às diretrizes do Decreto ${ }^{\circ}$. 5598/2005 (Brasil, 2005). A equipe do setor de Qualidade de Vida da empresa - composta por educador físico, pedagoga e assistente social - realizava atividades mensais com os aprendizes. Mediante encontros grupais, proporcionava aos adolescentes um espaço de orientação e reflexão acerca da experiência de aprendizagem e da realidade do mundo do trabalho. Trata-se de uma iniciativa da equipe, uma vez que esse tipo de acompanhamento não é uma exigência da empresa ou do decreto. Visando a uma qualificação do trabalho com os adolescentes, a equipe buscou consultoria junto a um grupo de pesquisa ligado a uma universidade. Desse trabalho, obtiveram-se os dados do estudo apresentado neste artigo.

A equipe de pesquisa utilizou as diretrizes da Inserção Ecológica (Cecconello \& Koller, 2004; Eschiletti Prati, Paula-Couto, Moura, Poletto \& Koller, 2008) para realizar seu ingresso no campo de investigação, o que permitiu investigar e conhecer os significados, os objetos, as relações e suas características no contexto investigado. $\mathrm{O}$ grupo de pesquisadoras, composto por cinco psicólogas, propôs um estudo seguido de intervenção com base na Abordagem Bioecológica do Desenvolvimento Humano - ABDH (Bronfenbrenner, 1979/1996, 2005), após duas reuniões para compreender a demanda da equipe de Qualidade de Vida da empresa. Essa abordagem, orientada pelo modo de descoberta, propõe-se a fornecer bases científicas para a criação de programas e políticas públicas que contraponham influências prejudiciais ao desenvolvimento das pessoas (Bronfenbrenner, 2005). No presente estudo, buscou-se promover a consciência crítica dos adolescentes aprendizes acerca do mundo do trabalho e da sua inserção nesse contexto.

Além disso, o processo de pesquisa foi orientado pelos princípios da inserção ecológica, a qual pressupõe o ingresso dos pesquisadores no campo de investigação. Esse método consiste em investigar as relações (processos) que as pessoas estabelecem durante seu crescimento pessoal ou social, no curso de sua história (tempo) em um determinado contexto. Ademais, permite conhecer os significados, os objetos e símbolos característicos das pessoas e do contexto (Cecconello \& Koller, 2004; Eschiletti Prati \& cols.). Seguindo esses 
pressupostos, o estudo foi realizado nas dependências da empresa não apenas junto aos adolescentes, mas também com os técnicos da equipe de Qualidade de Vida. Os procedimentos de coleta de dados foram realizados durante o período das atividades de aprendizagem dos adolescentes.

Após o levantamento de necessidades, realizou-se um encontro com a gerência do setor, a fim de se apresentar o plano de trabalho das pesquisadoras e de solicitar o consentimento mediante o termo de concordância da instituição. Uma vez dado o consentimento, as pesquisadoras iniciaram o trabalho por meio de observações dos dois grupos de adolescentes aprendizes coordenados pelos técnicos do setor de Qualidade de Vida. No total, eram 10 adolescentes, sendo que cinco exerciam suas atividades no turno da manhã (três meninas e dois meninos) e cinco, no turno da tarde (três meninos e duas meninas). Uma parte das pesquisadoras acompanhou o grupo do turno da manhã e a outra, o da tarde. A partir dessas observações, pôde-se conhecer o método de trabalho dos técnicos e suas formas de interação com os adolescentes.

Para estabelecer um vínculo com os aprendizes, a equipe de pesquisa realizou um encontro, no qual houve apresentação da proposta de trabalho, seguida da concordância dos adolescentes, o que se deu mediante assinatura do Termo de Consentimento Livre e Esclarecido. Inicialmente, procedeuse ao preenchimento do questionário biosóciodemográfico (Dell'Aglio, Poletto, De Antoni, Teodoro \& Koller, 2005). Ainda no primeiro encontro, foi proposta a realização de um grupo focal. Essa técnica foi escolhida por propiciar uma coleta de dados extensa e rica, sem perder o foco do estudo, e considerando a visão dos participantes a respeito de um evento ou experiência (De Antoni \& cols., 2001; Morgan, 1997). Buscou-se conhecer a percepção dos adolescentes acerca da experiência de aprendizagem na empresa, propondo-se questões norteadoras para conduzir a discussão.

Foram conduzidos quatro grupos focais, sendo dois com os adolescentes do turno da manhã e dois com os da tarde. No grupo da manhã, havia uma mediadora e duas observadoras e, no da tarde, uma mediadora e uma observadora. A observadora fazia anotações sobre a dinâmica do grupo (disposição na sala, características emocionais das verbalizações, comportamentos de cada participante, adolescentes que mais participavam) e acerca das principais idéias verbalizadas. As sessões, gravadas com o consentimento dos participantes, tiveram duração aproximada de uma hora e meia. Inicialmente, as pesquisadoras estabeleciam o rapport, fornecendo informações acerca dos objetivos do grupo focal, do andamento da atividade, do uso do gravador etc.

Os tópicos propostos aos adolescentes versaram sobre a adolescência, a motivação para ingressar no programa de aprendizagem, a experiência de ser aprendiz, o trabalho e o futuro profissional. As questões eram lançadas e a mediadora estimulava a participação de todos. Antes de passar ao tópico seguinte, procurava-se formular uma síntese da opinião dos participantes sobre o tema discutido a fim de confirmar as posições e contradições do grupo.

As sessões foram transcritas na íntegra e submetidas à análise de conteúdo (Bardin, 1979), buscando-se construir categorias temáticas e identificar semelhanças e diferenças dos participantes em relação às mesmas. Os nomes dos adolescentes são fictícios, a fim de manter o sigilo das informa- ções compartilhadas. Após a análise dos dados, foi realizada uma devolução de caráter técnico para a equipe da Qualidade de Vida da empresa e uma entrevista reflexiva coletiva com os adolescentes. Essa técnica foi utilizada com o intuito de aprimorar a fidedignidade, pois submete as percepções das pesquisadoras sobre os grupos focais à compreensão dos participantes (Szymanski, 2001). Além de proporcionar um momento de devolução, a entrevista reflexiva permitiu transmitir informações e suscitar reflexões a respeito do mercado de trabalho e da experiência de aprendizagem na empresa.

\section{Resultados e Discussão}

\section{Características biosociodemográficas dos participantes}

Dos 10 participantes, seis eram brancos e quatro eram negros. A média do número de irmãos foi de $1,90(S D=0,31)$. Em seis casos, os pais viviam juntos e, nos demais, eram separados. A maioria dos pais dos adolescentes tinha o Ensino Médio completo. Quanto às ocupações dos pais, foram citadas desde atividades operacionais, como serviços domésticos e zeladoria, até funções técnicas, como enfermagem e corretor de seguros. A renda familiar estava entre $\mathrm{R} \$ 1.000,00$ e $\mathrm{R} \$ 2.000,00$, e cada adolescente recebia uma bolsa-auxílio de $\mathrm{R} \$ 536,20$ na época da pesquisa. Oito deles relataram ajudar a família em despesas domésticas, além de utilizarem o dinheiro para consumo próprio.

Em relação à evasão escolar, uma menina relatou que foi expulsa devido a um episódio de violência na saída da escola e um menino referiu abandono durante alguns meses em virtude do falecimento de seu avô. Dos 10 participantes, apenas dois não haviam repetido o ano alguma vez.

Alguns adolescentes relataram experiências anteriores de trabalho, como prática de ensino no magistério, atendente de bar, trabalhos domésticos, babá - embora nem todas fossem remuneradas. Souberam do programa de aprendizagem na empresa por meio de conhecidos e parentes. Em relação às atividades executadas, dois atuavam na área de eventos, dois no setor de tecnologia da informação, três no setor administrativo, um na biblioteca e dois na comunicação. Relataram gostar do trabalho e sentir-se bem com a experiência de aprendizagem. Dentre os eventos de vida importantes, citaram o primeiro emprego, as perdas familiares e a separação dos pais. Quanto ao uso de drogas lícitas e ilícitas, oito afirmaram ter experimentado álcool, sendo que dois faziam uso eventual (um a três dias por mês) e três, uso frequente (quatro a 19 dias por mês). Em relação ao uso de cigarro, cinco já experimentaram e dois eram fumantes. Um dos participantes afirmou ter sido usuário de maconha por dois meses.

\section{Categorias temáticas}

Com base na análise de conteúdo das sessões dos grupos focais e nas questões norteadoras do estudo, foram criadas quatro categorias temáticas, que serão apresentadas a seguir: ser adolescente, aprendiz versus trabalhador, significado do trabalho e futuro profissional. As categorias 
temáticas não são excludentes, havendo conteúdos que perpassam uma e outra.

\section{Ser Adolescente}

A categoria "Ser adolescente" está relacionada com questões próprias da adolescência, envolvendo aspectos físicos, sociais e psicológicos. Os adolescentes sinalizam as mudanças e os aprendizados que ocorrem nesse momento do próprio desenvolvimento, referentes ao corpo e aos relacionamentos com os amigos e com a família. A adolescência é um período de mudanças biológicas, emocionais e sociais. Momento de assumir novos papéis, além de enfrentar novas tarefas evolutivas (Steinberg, 1999), conforme ilustra o seguinte depoimento:

Tipo, tu tá crescendo só que tu tem que aproveitar a tua adolescência porque eu acho que é a melhor fase que tu tem pra aprender e que tu tá absorvendo bastante... (Ana, 16 anos)

Os adolescentes apontaram que a família é fonte de apoio, afeto, orientação e compreensão. Diante dos conflitos que as mudanças dessa fase desenvolvimental provocam, a família foi percebida por boa parte dos entrevistados como um importante elemento da rede de apoio social e afetiva, como exemplifica o relato a seguir:

Aí a mãe vem e pergunta pra mim se eu quero conversar com ela. Ai eu converso, conto pra ela, ela me dá conselho, ela fala se eu fiz alguma coisa errada no meio da discussão. Ai eu vou tentar corrigir, sigo o conselho dela e do meu pai sempre. (Jean, 16 anos)

Nesse sentido, diversos pesquisadores assinalam o suporte familiar enquanto um fator que pode favorecer o desenvolvimento e o bem-estar dos adolescentes mesmo quando expostos a situações de estresse (Bronfenbrenner, 1979/1996; Hawley \& DeHann, 1996). Aspectos como coesão familiar, comunicação, qualidade do relacionamento entre pais e filhos e práticas educativas envolvendo afeto, reciprocidade, estabilidade, confiança e equilíbrio de poder são considerados fatores de proteção no processo de desenvolvimento.

Os participantes verbalizaram a satisfação de estar com pares e dos momentos de diversão. Expressaram maior autonomia em relação à infância e mostraram-se em fase de reflexão sobre seus valores quanto ao que consideram certo e errado. Relataram ter ganhado mais liberdade e, ao mesmo tempo, mais responsabilidades e necessidade de pensar no futuro, em quem são e o que desejam, conforme ilustra o depoimento a seguir.

Mas acho que ser adolescente é ... começar a ter mais responsabilidades, começar a pensar mais que não é mais criança, que tem que crescer, amadurecer ... (Marta, 16 anos)

Essas novas sensações e experiências vividas estão relacionadas à fase do desenvolvimento relativa à construção da identidade (Erikson, 1950/1987). Nesse período, o adolescente está voltado para saber quem é, quais são seus valores e o que fará profissionalmente. Nesse sentido, a vivência profissional é uma das bases para a construção da identidade dos adolescentes, os quais estruturam suas vidas a partir dos compromissos ideológicos, pessoais e laborais que assumem e presenciam em seu contexto de desenvolvimento. A partir dessa idéia, evidencia-se a particularidade dos adolescentes aprendizes, tendo em vista que, além dos conflitos da adolescência, está a vivência de trabalho - o que potencializa a fragilidade desse momento.

\section{Aprendiz versus trabalhador}

A categoria "Aprendiz versus Trabalhador" retrata as percepções dos adolescentes acerca da própria experiência de aprendizagem na empresa, incluindo semelhanças e diferenças entre os papéis de ser aprendiz e de ser trabalhador. De acordo com o Decreto n ${ }^{\circ} 5598 / 2005$ (Brasil, 2005), o contrato de aprendizagem visa à formação técnico-profissional e exige a manutenção das atividades escolares, diferenciando-se de uma relação de trabalho.

No intuito de cumprir o que prevê a lei, a empresa demonstrou preocupação em deixar claro que a experiência dos adolescentes era de aprendizagem e não de trabalho. Nesse sentido, havia o acordo implícito de não utilizar o termo "trabalho" para se referir às atividades executadas pelos adolescentes, tanto por parte destes quanto por parte da equipe da própria empresa. Tal posicionamento registra o comprometimento institucional com o trabalho protegido e pode estar manifestando as inseguranças quanto à possível fiscalização da Superintendência Regional do Trabalho e Emprego (SRTE). O termo "trabalho" toma conotação pejorativa para a empresa. Por outro lado, os jovens aprendizes possuem carteira de trabalho assinada, sob fiscalização do órgão responsável (SRTE), ou seja, sua condição está englobada na dimensão trabalho, conforme a verbalização:

Eu acho que tem, tem bastante diferença, porque quando a gente entrou aqui, o dr. João não falava trabalhar, ele falava aprender, então tudo o que a gente tá fazendo aqui a gente tá aprendendo, né, a gente não é profissional ainda, a gente tá aprendendo. (Marta, 16 anos)

Os participantes relataram que ser adolescente aprendiz é um privilégio de inserção no mercado de trabalho em relação a outros jovens e uma experiência importante para o futuro profissional. Sarriera e cols. (2001) descrevem o quanto as primeiras experiências laborais constituem o jovem em formação, pois servem como um modelo de referência. A maneira como o adolescente irá se relacionar em oportunidades futuras de trabalho sofre influência das primeiras atividades laborais, em termos de respeito às leis trabalhistas e submissão aos modelos exploratórios vigentes. Nesse sentido, Campos e Francischini (2003) descrevem que a experiência laboral dos adolescentes proporciona a internalização do sentido atribuído ao trabalho pelos adultos no contexto cotidiano em que o jovem se insere, já que este faz uso daqueles profissionais como referência. Os participantes entendem o funcionamento da empresa como modelo ideal de trabalho. Evidencia-se, portanto, que a referência central desses jovens é o modelo de trabalho protegido, referencial atípico frente a um universo de exploração da mão-de-obra infanto-juvenil. 
Famílias carentes de um suporte social adequado incorporam a lógica do trabalho infanto-juvenil em suas vidas como se este fosse um processo natural, minimizando os possíveis prejuízos dessa prática e enaltecendo seus supostos benefícios (Campos \& Francischini, 2003).

Os participantes manifestaram que ser trabalhador e aprendiz são experiências semelhantes e diferentes ao mesmo tempo. Esse resultado é consistente com aqueles relatados por Oliveira e Robazzi (2001). Esses autores indicaram que não há distinção clara entre o trabalho que os adolescentes realizam e aquele desenvolvido pelos adultos. Os participantes do presente estudo consideram que a vivência de ser adolescente aprendiz não se diferencia de qualquer outro trabalho. No entanto, também percebem que o jovem aprendiz sofre menor cobrança, pois o trabalhador ingressaria no mercado preparado para executar sua função, enquanto que o aprendiz estaria em processo exclusivo de aprendizado, conforme ilustra o seguinte depoimento:

Bom, o meu ponto de vista é que aprendiz tá aqui pra aprender e o trabalhador tá pra trabalhar. Ou seja, o aprendiz tá aqui pra tropeçar, cair, se levantar e seguir em frente e aprender pra se profissionalizar pro mercado. E o trabalhador já vem profissionalizado pra trabalhar. (Antenor, 15 anos).

Em outras passagens do grupo focal, os adolescentes discutiram as semelhanças entre trabalhador e aprendiz. A maioria percebe que os trabalhadores seguem aprendendo ao longo do exercício profissional, o que também os tornariam, de alguma forma, aprendizes. Evidenciou-se, portanto, uma contradição quanto às terminologias trabalhador e aprendiz porque tanto o trabalho adulto possui um caráter de aprendizado contínuo como o trabalho adolescente está relacionado com responsabilidades e deveres. Nesse sentido, os participantes descreveram que as atividades realizadas na empresa se intensificaram com o passar do tempo, tornandose mais complexas, de forma que o grau de responsabilidade pela execução das mesmas aumentou. Somam-se a isso os efeitos da rotina de quem assume um papel dentro de uma organização. Sendo assim, o aprendiz estaria apropriado de um conhecimento técnico e específico, num grau semelhante ao do trabalhador. Essas constatações evidenciam a permeabilidade das terminologias aprendiz e trabalhador, contraditórias quando confrontadas com a realidade cotidiana dos adolescentes. A verbalização a seguir exemplifica:

Eu acho que trabalhador também aprende, porque na verdade a gente nunca terminou de aprender tudo, sempre tem alguma coisa pra aprender. (Diana, 16 anos)

... Tô trabalhando até mais do que antes. Porque, logo no início, até o pessoal, meio assim, não dava muito trabalho, né? Mas agora a gente tá na correria. Todo o dia tem serviço. Isso mudou bastante pra mim. (José, 16 anos)

Ao mesmo tempo em que trabalho é fonte de amadurecimento psicológico, intelectual e de socialização, complementando a ação da escola para os adolescentes, pode causar o fenômeno da "adultização" (Guimarães \& Romanelli, 2002; Oliveira \& Robazzi, 2001). O elevado número de atividades a que estão expostos, envolvendo tarefas laborais, familiares e escolares - em detrimento de um espaço de lazer e desenvolvimento - pode levar os jovens a ser acometidos por uma carga de responsabilidades para além de suas capacidades (Fischer, Oliveira \& cols., 2003; Oliveira \& Robazzi, 2001).

Eu acho que tem muito pouca diferença. O negócio dos horários é tudo a mesma coisa. Tem que ser responsável, tem que tá sempre no horário. Quando tu é chamado, tu tem que cumprir como os outros, como os demais. Tem que ser responsável como um trabalhador normal. (Lucas, 16 anos)

\section{Significado do trabalho}

A categoria "Significado do trabalho" refere-se à opinião dos adolescentes sobre o que é o trabalho e o que este representa. Os aprendizes apontaram que o trabalho significa sobrevivência, independência financeira, possibilidade de melhorar de vida, formação profissional privilegiada e valor moral, entre outros. Ressalte-se que os participantes tiveram dificuldade para começar a discutir essa temática.

Os jovens vêem o trabalho como um meio de ajudar as famílias, de adquirir independência financeira e uma maneira de conquistar a liberdade. Isso está relacionado ao que afirmaram comprar com a bolsa-auxílio: roupas, calçados, aparelhos eletrônicos, além de gastos com diversão. Alguns relataram, ainda, economizar parte do valor recebido. Esses achados estão de acordo com alguns estudos (Asmus \& cols., 2005; Campos \& Francischini, 2003; Guimarães \& Romanelli, 2002; Oliveira \& Robazzi, 2001) que afirmaram que os jovens buscam o trabalho como forma de consumir o que seus pais não têm condições de lhes dar. Além da questão do consumo, a possibilidade de melhorar de vida apareceu também nos relatos dos adolescentes, algo já encontrado em outros estudos (Oliveira \& cols., 2001; Fischer, Oliveira \& cols., 2003; Sarriera \& cols., 2001).

O significado atribuído ao trabalho está diretamente relacionado à motivação para a busca de uma ocupação. Quando questionados sobre a motivação para participarem do programa de aprendizagem, os adolescentes relataram incentivo da família, busca pelo primeiro emprego e por novas experiências e conhecimentos, curiosidade em relação ao mercado de trabalho e ambiente laboral agradável. Guimarães e Romanelli (2002) identificam motivações semelhantes para a busca do trabalho por parte dos jovens.

O incentivo da família é comum nas classes populares, em que os genitores entendem que cumpriram sua obrigação de prover o estudo dos filhos ao término do Ensino Fundamental. Acreditam que os filhos precisam iniciar a atividade laboral a partir desse período, a fim de arcarem com seus próprios gastos e, por vezes, auxiliar nas despesas domésticas (Guimarães \& Romanelli, 2002). Apesar do incentivo da família ser apontado como motivação, também há casos em que a iniciativa própria foi mencionada.

Os participantes consideraram que o trabalho consiste em compromisso e responsabilidade. Esses atributos estão relacionados ao processo de amadurecimento pelo qual estão atravessando e ao papel que passam a desempenhar na família, o que exige ao mesmo tempo a aquisição de autonomia 
e a independência. Demonstraram compreender que estão crescendo, tornando-se provedores das necessidades próprias e dos familiares e de que são menos dependentes dos pais. Essas ideias aparecem nos seguintes depoimentos:

Bom, eu acho que é uma responsabilidade que a gente assume a partir do momento que se torna necessário, né. Necessidades a gente tem bastante e se a gente não trabalha a gente não tem como resolver elas. (...) Mais provavelmente, na maior idade, vai sair de casa, ter família, ai o momento de começar a trabalhar. (Jean, 16 anos)

É pra tu aprender a conviver no meio de pessoas diferentes, pra não ficar sempre na família, embaixo da família assim. Tu vai aprendendo, que um dia a tua família vai embora e tu vai ficar sozinho. (Antenor, 15 anos)

Para os adolescentes, o trabalho também significa o conhecimento que se adquiriu ao longo da vida, desenvolvimento pessoal e o ato de "colocar a teoria em prática". Tais afirmações expressam a idéia de uma continuidade entre estudo e trabalho. Sobre a relação entre esses dois conceitos, alguns participantes, quando questionados se estudar é trabalho, afirmaram que se assemelham. Relataram que consideravam a oportunidade na empresa como uma formação profissional privilegiada, que não está disponível a todos os jovens. Fischer, Oliveira e cols. (2003) afirmam que essa concepção de trabalho enquanto aprendizagem é apontada pelos jovens como um ganho no longo prazo por meio da preparação para a vida e para o mercado de trabalho.

Constatou-se ainda, a partir dos relatos, a submissão à lógica empresarial, a questão da hierarquia e da obediência - "saber se pôr no seu lugar de empregado" (Diana, 16 anos). Em relação a esse aspecto, Oliveira e Robazzi (2001) ressaltam a necessidade, muitas vezes imposta pelas empresas, do adolescente trabalhador manter-se dócil, disposto para o trabalho, obediente e inserido em uma relação de dominação/subordinação, a qual permite que o modelo social vigente se perpetue. Essa necessidade de sujeição às leis do mercado de trabalho é citada por Asmus e cols. (2005), os quais afirmam que os jovens aprendem rapidamente a exigência de tal condição para ganhar dinheiro e garantir o sustento. Além disso, de acordo com Fischer e cols. (2005), os adolescentes trabalhadores que apresentam menor autoridade de decisão acabam trabalhando mais - realizando horas-extras - do que aqueles que possuem maior autoridade de decisão. Sendo assim, a falta de controle no trabalho pode gerar consequências para os adolescentes, como implicações na construção da identidade de trabalhador, submissão a condições inseguras de trabalho, passividade diante de relações laborais, entre outras.

A lógica empresarial, que organiza o mercado de trabalho, influencia a formação da identidade de trabalhador. Nardi e Yates (2005), em um estudo com jovens empregados no setor tecnológico (informática, internet e telecomunicações) e no bancário, verificaram a incorporação do discurso gerencial e a constituição de uma lógica individualista. Outro aspecto igualmente relacionado à formação da identidade de ser trabalhador é o atributo moral conferido ao trabalho como algo dignificante e que traz crescimento, também encontrado em outros estudos (Oliveira \& cols., 2001; 2005). Tal atributo seria uma construção histórica em relação aos benefícios do trabalho (Oliveira \& Robazzi, 2001). Esse significado aparece no seguinte depoimento:

... A minha familia sempre mexia comigo, ah, que já tava na hora de eu trabalhar, que era pra mim deixar de ser vagabundo. Só ia pro colégio e não fazia mais nada. Em casa, não queria ajudar (...) Ai eu resolvi me inscrever no projeto. Dei a sorte de conseguir porque não são muitas vagas. Dessas vagas, eu consegui ficar entre os 10. Então, pra mim essa foi o mais interessante assim. Eu ter o meu salário, saber, aprender a administrar meu dinheiro. E sair das fraldas um pouco. (José, 16 anos)

Não apareceram afirmações no sentido do trabalho enquanto atividade humana por excelência, que proporciona prazer, realização pessoal, expressão da criatividade e exercício de um papel na sociedade (Jacques, 1995). Os participantes trouxeram apenas idéias associadas ao emprego e à sobrevivência, relacionadas à concepção do trabalho como mercadoria, ou seja, venda da força de trabalho (Antunes, 1998). Nesse sentido, o significado do trabalho para os participantes, vazio de sentido, parece resumir-se ao sustento econômico e ao consumo, além do seu valor moral, com a idéia de que "ser bom" é ser trabalhador. Diante disso, faz-se necessário refletir acerca da identidade de trabalhador que os participantes estão construindo, uma vez que fica reduzida à provisão de necessidades, sem a visão do trabalho enquanto atividade humana por excelência, com promoção de mudanças na natureza/sociedade e geração de prazer e significado para quem a executa.

\section{Futuro profissional}

A categoria "Futuro profissional" está relacionada às expectativas dos adolescentes sobre o trabalho e as atividades que desejam desenvolver. Todos os adolescentes manifestaram interesse em continuar trabalhando após o término do contrato de aprendizagem na empresa. Entretanto, demonstraram certa indefinição quanto à escolha profissional.

Evidenciaram-se idealizações tanto em relação à empresa onde realizaram suas atividades como aprendizes quanto à formação profissional. Muitos manifestaram interesse em continuar trabalhando na empresa, apresentando como justificativas o ambiente de trabalho agradável, as possibilidades de aprendizado e o clima organizacional de acolhimento. Essas justificativas, entretanto, estão relacionadas ao contexto de trabalho protegido e remetem às idealizações construídas pelos participantes nessa primeira experiência de trabalho, como exemplifica o depoimento:

Eu particularmente não tenho uma profissão assim que eu já escolhi, definida na minha cabeça. Mas depois que eu comecei a trabalhar no [empresa], eu gostei muito, tô aprendendo bastante, talvez até pretendo trabalhar por aqui mesmo [empresa], depois de terminar os dois anos de estágio. (Lucas, 16 anos)

Além disso, os participantes citaram com bastante ênfase o desejo de formar-se em profissões de curso superior, como Direito, Computação, Enfermagem e Educação Física. Oli- 
veira e cols. (2001) também encontraram a idéia de sucesso profissional e possibilidade de melhoria de vida associada à formação em nível superior. Outro estudo com adolescentes trabalhadores verificou idealizações acerca do mercado de trabalho e da escolha profissional marcadas pela fantasia (Sarriera \& cols., 2001).

Uma das consequências da idealização seria a dificuldade de perceber o mercado de trabalho com as suas reais exigências, incongruências e limitações. Os participantes não parecem identificar as características macroeconômicas que regem o mercado laboral, assim como a realidade social do Brasil. O grau de escolarização e a qualificação permanente foram apontados como uma espécie de garantia de empregabilidade, fato já discutido por Oliveira e cols. (2001).

Os adolescentes verbalizaram o desejo de ser bons profissionais, respeitados, com credibilidade e competência. Tais atributos denotam elementos presentes na construção da identidade profissional. A inserção no mundo do trabalho possui valor social e reproduz o imaginário coletivo de valorização moral do ser trabalhador. A identidade do trabalhador se constrói precocemente pela identificação com modelos adultos e pela inserção concreta no mundo do trabalho (Jacques, 1995).

\section{Reflexões com os adolescentes}

Para a integridade física e mental dos jovens trabalhadores, faz-se necessário que sejam informados sobre a saúde do trabalhador e seus direitos à qualidade de trabalho. Essas informações devem ser transmitidas por meio de metodologias participativas, nas quais o processo de aprendizagem colabora para a formação de uma consciência crítica nos jovens (Asmus \& cols., 2005) - a entrevista reflexiva ou intervenção utilizada neste estudo foi um passo nesse sentido.

Percebeu-se a importância de um momento para refletir sobre as primeiras experiências de trabalho, fato também constatado por alguns participantes. Outros adolescentes, entretanto, parecem não ter percebido a necessidade de espaços para discussão e reflexão acerca da adolescência e do mundo do trabalho, conforme verbalização a seguir:

Eu gostei bastante. Coisas que eu nunca tinha parado para pensar... Eu nunca imaginava ... Desde então tenho refletido mais sobre o que quero para minha vida, sobre o que passou ...Para começar a evoluir. (Jean, 16 anos)

As pesquisadoras selecionaram alguns aspectos relevantes percebidos nos grupos focais, com o objetivo de proporcionar reflexão a respeito dos mesmos: necessidade de administrar o dinheiro; dissociação aprendiz versus trabalhador; desconhecimento do mercado de trabalho e da legislação; falta de um projeto profissional. Os adolescentes verbalizaram sua dificuldade de perceber as implicações do mercado sobre sua vida profissional e a necessidade de pensar sobre seu futuro laboral. Após reflexão conjunta com as pesquisadoras, puderam dar-se conta de que, embora em um contexto de trabalho protegido, suas atividades na empresa estão inseridas na dimensão trabalho. Ressalta-se a pertinência de orientações oferecidas pelas pesquisadoras a respeito do mundo do trabalho e da formação profissional, conforme ilustra depoimento a seguir:

Agora outras coisas ficaram mais claras a respeito do mercado de trabalho, têm coisas que vocês comentaram que a gente não sabia, cairam as fichas. (Jean, 16 anos)

\section{Considerações Finais}

A equipe da empresa que acompanhava os adolescentes, diante de algumas dificuldades ao tratar demandas relativas à formação da identidade pessoal e ocupacional, buscou orientações junto a psicólogos pesquisadores. O processo de assessoria e pesquisa apontou a necessidade de que o treinamento oferecido contemplasse um espaço grupal para reflexão, a fim de que os jovens pudessem pensar sobre sua experiência de aprendizagem e posicionar-se criticamente frente às experiências laborais. Também foi sugerida a inclusão de um psicólogo na equipe, profissional que possui instrumental teórico-prático para complementar as atividades realizadas - uma necessidade da própria equipe, que buscou assessoria externa da Psicologia.

Verificou-se a necessidade de se trabalhar a administração do dinheiro com os adolescentes, de modo que estes possam fazer uso desse benefício em prol do seu futuro e bem-estar. A bolsa recebida e o suporte financeiro familiar situam esses adolescentes em uma zona de conforto. Por outro lado, questiona-se até que ponto esses jovens, ao encerrar seu contrato de aprendizagem, terão garantidos seus direitos como trabalhadores, ou mesmo a colocação no mercado de trabalho. As expectativas dos adolescentes em relação ao futuro laboral revelaram medo e insegurança e, ao mesmo tempo, idealização por acreditarem que qualificação pode garantir boas colocações. A desinformação a respeito do mundo do trabalho contemporâneo pode impactar estes jovens ao buscarem outras oportunidades. Torna-se necessário, portanto, ampliar a noção de mercado de trabalho e promover espaços de reflexão que propiciem a elaboração de um projeto profissional.

Não foram realizadas observações das atividades de aprendizagem executadas pelos adolescentes, uma vez que não era o objetivo central desse estudo. Entretanto, sugerese que futuros estudos incluam a observação do contexto de trabalho aprendiz com o intuito de verificar os possíveis riscos à saúde, o potencial de aprendizagem e de expressão criativa dos adolescentes.

Constataram-se inadequações da empresa ao aplicar a legislação. Tal aspecto foi visualizado na insegurança da empresa em utilizar o termo "trabalho", conferindo conotação pejorativa ao mesmo e tomando a atividade laboral - constituinte e formadora do ser humano - como negativa. Os jovens aprendizes possuem carteira assinada, horário de trabalho, remuneração mensal, funções e responsabilidades. Essas características assemelham-se às atividades executadas pelo trabalhador. Nesse caso, o adolescente aprendiz é um cidadão privilegiado por estar inserido no mercado de trabalho formal, frente a um quadro de significativa fragilidade: desemprego, escassas políticas de geração de renda, relações de trabalho 
precárias, políticas sociais com pouco investimento governamental, fracos mecanismos de inserção dos jovens no mercado de trabalho e maiores exigências do nível de escolaridade (Lima \& Minayo-Gomes, 2003). Estabelece-se, nesse momento, uma dissociação: os jovens possuem carteira assinada e não estão trabalhando. Todavia, anular a atividade do adolescente enquanto trabalho não lhe garante proteção. Questiona-se até que ponto, na prática, o contrato de aprendizagem vivenciado pelo jovem na condição de aprendiz está sendo legitimado, uma vez que o aspecto produtivo não deveria sobrepor-se ao educativo. Evidencia-se um problema macroestrutural nas relações de trabalho, pois a atividade laboral deve ser protegida não apenas na adolescência, mas no decorrer de todo o período produtivo do trabalhador. Na tentativa de ajudar, muitas propostas e programas acabam por legitimar condutas exploratórias. Tal abordagem pode estar reforçando o quadro de desrespeito às leis trabalhistas e submissão aos modelos exploratórios vigentes, no momento em que a categoria trabalho protegido é restringida aos adolescentes, enquanto deveria ser ampliada para todo e qualquer trabalhador.

A experiência de ser adolescente aprendiz faz parte da construção da identidade de ser trabalhador. Uma das motivações do jovem para o trabalho é a valorização social desta atividade, percebida como uma situação privilegiada para a formação profissional e para o desenvolvimento pessoal. Nesse sentido, é pertinente que os adolescentes em contrato de aprendizagem sejam reconhecidos como aprendizes e trabalhadores.

Os programas de acompanhamento psicossocial junto a adolescentes trabalhadores podem promover um espaço de reflexão que desenvolva o posicionamento crítico destes jovens. Ao se inserirem no mundo do trabalho, a postura questionadora permitirá que não perpetuem práticas de desrespeito às leis trabalhistas e tomem sua atividade como formadora constante de sua própria identidade como sujeito e cidadão. O trabalho é construtor da subjetividade do ser humano, e, portanto, deve ser tomado como tema de relevância social.

\section{Referências}

Antunes, R. (1998). Adeus ao trabalho? Ensaio sobre as metamorfoses e a centralidade do mundo do trabalho ( $5^{\mathrm{a}}$ ed.). São Paulo: Cortez.

Asmus, C. I. R. F, Raymundo, C. M. R., Barker, S. L., Pepe, C. C. C. A., \& Ruzany, M. H. (2005). Atenção integral à saúde de adolescentes em situação de trabalho: lições aprendidas. Ciência \& Saúde Coletiva, 10, 953-960.

Bardin, L. (1979). Análise de conteúdo. Lisboa: Edições 70.

Brasil (1990). Estatuto da Criança e do Adolescente - Lei Federal 8069/1990. Brasília: Diário Oficial da União

Brasil (2005). Decreto 5598/2005. Brasília: Diário Oficial da União.

Bronfenbrenner, U. (2005). The bioecological theory of human development. Em U. Bronfenbrenner (Ed.), Making human beings human: Bioecological perspectives on human development (pp. 3-15). Thousand Oaks: Sage.
Bronfenbrenner, U. (1996). A ecologia do desenvolvimento humano: experimentos naturais e planejados (M. A. V. Veronese, Trad.). Porto Alegre: Artes Médicas. (Trabalho original publicado em 1979)

Campos, H. R., \& Francischini, R. (2003). Trabalho infantil produtivo e desenvolvimento humano. Psicologia em Estudo, (Maringá), 8(1, especial), 119-129.

Cecconello, A. L. M., \& Koller, S. H. (2004). Inserção ecológica na comunidade: uma proposta metodológica para o estudo de famílias em situação de risco. Em S. Koller (Ed.), Ecologia do desenvolvimento humano: pesquisa e intervenção no Brasil (pp. 267-291). São Paulo: Casa do Psicólogo.

Codo, W. (1992). O que é alienação?(8 ${ }^{\mathrm{a}}$ ed.). São Paulo: Brasiliense.

De Antoni, C., Martins, C., Ferronato, M. A., Simões, A., Maurente, V., Costa, F., \& Koller, S. H. (2001). Grupo focal: método qualitativo de pesquisa com adolescentes em situação de risco. Arquivos Brasileiros de Psicologia, 53, 38-53.

Dell'Aglio, D. D., Poletto, M., De Antoni, C., Teodoro, M. L. M., \& Koller, S. H. (2005). Questionário biosociodemográfico [manuscrito não publicado]. Projeto PRONEX/Fapergs/CNPq, Centro de estudos Psicológicos sobre Meninos(as) de Rua, Instituto de Psicologia, UFRGS. Disponível em www.psicologia.ufrgs.br/ cep_rua.

Erikson, E. H. (1987). Infância e sociedade (G. Amado, Trad.) ( $2^{\text {a }}$ ed.). Rio de Janeiro: Zahar (Trabalho original publicado em 1950).

Eschiletti Prati, L., Paula-Couto, M. C. De P., Moura, A., Poletto, M., \& Koller, S. (2008). Revisando a inserção ecológica: uma proposta de sistematização. Psicologia: Reflexão \& Crítica, 21, 160-169.

Fischer, F. M., Oliveira, D. C., Teixeira, L. R., Teixeira, M. C. T. V., \& Amaral, M. A. (2003). Efeitos do trabalho sobre a saúde de adolescentes. Ciência \& Saúde Coletiva, 8, 973-984.

Fischer, F. M., Martins, I. S., Oliveira, D. C., Teixeira, L. R., Latorre, M. R. D., \& Cooper, S. P. (2003). Occupational accidents among middle and high school students of the state of São Paulo, Brazil. Revista de Saúde Pública, 37, 351-356.

Fischer, F. M., Oliveira, D. C., Nagai, R., Teixeira, L. R., Junior, M. L., Latorre, M. R. D. O., \& Cooper, S. P. (2005). Job control, job demands, social support at work and health among adolescent workers. Revista de Saúde Pública, 39, 245-53.

Guimarães, R. M., \& Romanelli, G. (2002). A inserção de adolescentes no mercado de trabalho através de uma ONG. Psicologia em Estudo, (Maringá), 7, 117-126.

Hawley, D. R., \& DeHann, L. (1996). Toward a definition of family resilience: Integrating life span and family perspectives. Family Process, 35, 283-298.

Jacques, M. G. C. (1995). Saúde mental e trabalho: a construção da identidade de trabalhador. Cadernos de Sociologia, 7, $167-$ 175.

Lima, S.M., \& Minayo-Gomes, C. (2003). Modos de subjetivação na condição de aprendiz: embates atuais. História, Ciências e Saúde, Manguinhos, 10, 931-53

Morgan, D. (1997). Focus groups as qualitative research. Newbury Park: Sage.

Nardi, H. C., \& Yates, D. B. (2005). Transformações contemporâneas do trabalho e processos de subjetivação: os jovens face à nova economia e à economia solidária. Estudos de Psicologia, 10, 95-103. 
Oliveira B. R. G., \& Robazzi, M. L. C. C. (2001). O trabalho na vida dos adolescentes: alguns fatores determinantes para o trabalho precoce. Revista Latino-americana de Enfermagem, 9, 83-89.

Oliveira, D. C., Sá, C. P., Fischer, F. M., Martins, I. S., \& Teixeira, L. R. (2001). Futuro e liberdade: o trabalho e a instituição escolar nas representações sociais de adolescentes. Estudos de Psicologia, 6, 245-258.

Oliveira, D. C., Fischer, F. M., Teixeira, M. C. T. V., \& Amaral, M. A. (2003). A escola e o trabalho entre adolescentes do ensino médio da cidade de São Paulo: uma análise de representações sociais. Psicologia: Teoria e Prática, 5, 27-39.

Oliveira, D. C., Fischer, F. M., Amaral, M. A., Teixeira, M. C. T. V., \& Sá, C. P. (2005). A positividade e a negatividade do trabalho nas representações sociais de adolescentes. Psicologia: Reflexão \& Crítica, 18, 125-133.
Sarriera, J. C., Silva, M. A., Kabbas, C. P., \& Lopes, V. B. (2001). Formação da identidade ocupacional em adolescentes. Estudos de Psicologia, 6, 27-32.

Steinberg, L. (1999). Adolescence. Boston: McGraw-Hill.

Szymanski, H. (2001). A entrevista reflexiva. Revista Psicologia da Educação, 10, 193-215.
Recebido em 11.10.07

Primeira decisão editorial em 17.06.08

Versão final em 23.07.08

Aceito em 11.03.09 